\title{
ALGUNOS INTERROGANTES SURGIDOS A RAIZ DEL TELETRABAJO PRODUCTO DE LA PANDEMIA COVID-19
}

\begin{abstract}
Juan Ignacio Caminos ${ }^{1}$
Sumario: I. El coronavirus, protagonista del año. II. El teletrabajo durante la pandemia: ¿decisión, obligación o imposición? III. El teletrabajo bajo la óptica de la informalidad y el género: ¿La pandemia nos afecta por igual? IV. Apuntes para el futuro: ¿En qué contexto tecnológico enfrentamos el teletrabajo de la pandemia? VI. Conclusión. VII. Bibliografía.
\end{abstract}

Resumen: Uno de los impactos de la pandemia COVID-19 ha sido la obligación subrepticia de adoptar la modalidad de teletrabajo a raíz de las medidas de confinamiento obligatorio decretadas. Esta metamorfosis de las modalidades de trabajo se ha presentado por demás ríspida desde el plano jurídico y social. El objetivo del presente trabajo es analizar los efectos de la experiencia obligada de teletrabajo desde tres ejes: ius variandi, género e informalidad y brecha digital. .

Palabras clave: Teletrabajo. Ius Variandi. Informalidad. Igualdad, Brecha

\section{I. -El Coronavirus, protagonista del año.}

Poco puede agregarse a lo que ya mucho se ha hablado sobre los impactos del coronavirus en el mundo del trabajo. De todos los informes, artículos doctrinarios, y debates (virtuales), podemos afirmar que el año 2020 será recordado (entre otras cosas) por aquel sacudón inesperado que obligó a reinventar el trabajo y a improvisar su prestación de forma remota.

El teletrabajo, que previo a la pandemia era considerado como una modalidad sumamente atípica de trabajo, se convirtió de la noche a la mañana en una especie de comodín para que las empresas pudieran continuar con su actividad económica y productiva, mientras una voraz pandemia asechaba las calles de nuestro país y del mundo. En simultáneo, legisladores, sindicatos, empresarios, doctrinarios e investigadores retomaron algunas viejas discusiones sobre el teletrabajo, a los fines de otorgarle un marco normativo específico a esta modalidad de ejecución de tareas. Todo, a causa del coronavirus.

1 Abogado (U.N.C.); colaborador en Proyecto de Investigación de la Secretaría de Ciencia y Tecnología (U.N.C.); miembro de la Delegación Argentina de Jóvenes Juristas de la Sociedad Internacional de Derecho del Trabajo y de la Seguridad Social (S.I.D.T.S.S.);miembro de la Asociación Argentina de Derecho del Trabajo y la Seguridad Social (A.D.T.S.S.);miembro de la Comunidad CIELO Laboral. E-mail de contacto: juanignaciocaminos@gmail.com. 
Durante el devenir del presente artículo, se expondrán algunos interrogantes desde distintas aristas del vivenciado teletrabajo atípico y obligatorio producto de la pandemia COVID-19 (ordenadas de forma aleatoria, sin ningún orden de prevalencia) cuya finalidad no es la de aseverar una postura, sino que por el contrario, encuentra una intención de disparar ideas que estimo no deberían de estar ausentes en la mesa de discusión sobre el futuro (o mejor dicho, presente) del trabajo. Como dice una conocida canción de nuestro rock nacional: "El futuro llegó, hace rato...", (aunque nos negábamos a verlo).

\section{El teletrabajo durante la pandemia: ¿decisión, obligación o imposición?}

Pese a que nuestra provincia de Córdoba se encuentre en líneas generales transitando por la fase que importa una flexibilización de la "cuarentena" (que se encuentra supeditada a la habilitación de las actividades que el Centro de Operaciones de Emergencia disponga), el retorno a la modalidad laboral presencial absoluta es inviable en el futuro próximo. Por ello las empresas se encuentran en la obligación de implementar protocolos de trabajo que establezcan turnos rotativos de su personal para disminuir el riesgo de contagios del virus COVID-19.

En este contexto, el teletrabajo atípico y obligatorio, instaurado producto de la pandemia COVID-19, aún sigue siendo una modalidad en boga, y lejos de encontrarse superado por el transcurso del tiempo de confinamiento o distanciamiento, se ha perfilado para instalarse, a priori, durante lo que le reste a este año $2020 .{ }^{3}$ Ante su sorpresiva aparición e impuesta continuidad, la doctrina ius/aboralista encuentra posturas enfrentadas sobre la pertinencia (o no) de la imposición empresarial de forma obligatoria el teletrabajo durante la pandemia.

Arese $^{4}$, entiende que a partir de un análisis literal de la letra de la normativa de emergen$c a^{5}$ que refieren a la instrumentación del teletrabajo en el marco de la crisis, surge un deber imperativo dirigido hacia los trabajadores, en aras de que estos pacten con su empleador las condiciones del teletrabajo domiciliario, en la medida de que las posibilidades así lo permitan.

Agrega además, que la obligación impuesta se erige bajo un apercibimiento de que su negativa o reticencia pueda llegar a ser considerada como una "mala fe" contractual. No obstante, en el análisis del tenor literal de las normas, el referido autor advierte que lo ordenado importa para la mayoría de los trabajadores "un cambio sustancial en las condiciones de trabajo", que requerirá de un condicionamiento temporal, para ajustar todas aquellas rispideces que su aplicación importe.

Gnecco $0^{6}$ por su parte, funda su posición a partir del análisis de la resolución 202/2020 emitida por el Ministerio de Trabajo, Empleo y Seguridad Social, la que le permite soste-

\footnotetext{
2 Canción “Todo un palo” de Patricio Rey y sus Redonditos de Ricota publicada en el álbum "Un baión para el ojo idiota” en el año 1987.

3 Para mayor abundamiento, puede consultarse la noticia del portal IPROUP, titulada: "Cuando tengas que volver, podrás no volver: qué empresas evalúan seguir con home office durante todo el 2020". Disponible en: https://www.iproup.com/innovacion/13692-empleo-home-office-que- empresas-haranteletrabajo-todo-2020.

4 ARESE, Cesar, "Cinco preguntas sobre el "jus variandi COVID-19" y la Res. METSS 279/2020", Revista de Derecho Laboral-Actualidad, Suplemento Digital n³: "El impacto del coronavirus en las relaciones laborales", Cita: RC D 1561/2020, Editorial Rubinzal Culzoni, Santa Fe, $2020 .$.

5 El autor en su artículo hace referencia a los decretos de necesidad y urgencia 297/2020 y 325/2020, las resoluciones 202, 207, 219 y 279 del Ministerio de Trabajo, Empleo y Seguridad Social de la Nación; la resolución 21 de la Superintendencia de Riesgos del Trabajo y la decisión administrativa 390 de la Jefatura de Gabinete.

6 GNECCO, Lorenzo, "Suspensión y despido en la emergencia", Revista de Derecho Laboral- Actualidad, Suplemento Digital n4: "El impacto del coronavirus en las relaciones laborales", Cita: RC D 1597/2020, Editorial Rubinzal Culzoni, Santa Fe, 2020.
} 
ner que los trabajadores dispensados de asistir a sus establecimientos laborales a raíz de la pandemia, debían pautar de buena fe con su empleador las condiciones de trabajo para continuar ejecutando sus tareas habituales u otras análogas desde su lugar de aislamiento, en la medida en que estas pudieran ser realizadas bajo esta modalidad. El autor plantea entonces, que se trata de una especie de "...ius variandi por modificación temporal convenida del contenido contractual con fundamento en razones de bien común",

que se extiende no solamente al lugar de trabajo, sino que también hacia las tareas desarrolladas por el trabajador (con la limitación de que éstas no pueden resultar irracionales, ni abusivas).

Duarte ${ }^{7}$, encauzándose bajo la preferente tutela que le corresponden a los trabajadores conforme los lineamientos dictados por la Corte Suprema de Justicia de la Nación, hace un especial ahínco en la necesidad de compensar adecuadamente a los teletrabajadores que presten servicios desde su domicilio producto de la pandemia; resaltando que la modalidad impuesta acarrea serios trastornos psicosociales y demás consecuencias sensiblemente disvaliosas para los trabajadores. Culmina su posición arguyendo sobre la insuficiencia de la sola "buena fe" de las partes para enfrentar la experiencia del teletrabajo producto de la pandemia, visto que esto implica una "exigencia muy tierna, aunque poco real, ya que en la relación de trabajo todo aquello que se deja librado a la parte individual del contrato se expresa en la práctica como pura unilateralidad patronal".

En cuanto a la buena fe en el contexto de la pandemia, Cuadrado ${ }^{8}$ entiende que nos encontramos frente a una crisis que ha puesto a prueba a las organizaciones de trabajo, por lo que trabajadores y empleadores vivencian un insuperable momento para aplicar dos principios generales del derecho: solidaridad y la buena fe. Para lograrlo, deberán de ajustar sus acciones y extremar sus esfuerzos de forma conjunta, bregando ambas partes por un objetivo en común: la permanencia y la continuidad de las fuentes de trabajo.

La normativa de emergencia emitida durante la pandemia no dio tiempo para lo importante y se dedicó a regular lo urgente: contrarrestar los efectos perniciosos de un virus que avanzó (y continua avanzando) de forma atroz.

Ante la imperiosa necesidad de resguardar la salud y seguridad de los habitantes de nuestro territorio, evitar la propagación del virus y conservar las fuentes de trabajo, las medidas adoptadas por el Gobierno Nacional durante el contexto pandémico han sido estructuradas bajo la histórica piedra angular de las relaciones jurídicas: la buena fe.

Enseña Capón Filas ${ }^{9}$, que siempre resulta esperable y exigible (tanto del empleador, como del trabajador), que sus conductas se erijan bajo los criterios de colaboración, solidaridad, y el módulo estándar de la buena fe, visto que su fin último es el de hominizarse a través de la relación de trabajo. Por lo tanto, la buena fe adquiere supina importancia, ya que a partir de ella se englobará un catálogo de deberes jurídicos laborales esperables de los contratantes, que los dotarán de confianza durante la prolongación de la relación que los une, y les permitirá a las partes lograr una civilización solidaria.

7 DUARTE, David. “El trabajo en el lugar de aislamiento por COVID-19, ¿̨es teletrabajo?”, Revista socio-laboral Catorce Bis, Edición N 58. Primer semestre 2020,AADTySS-Córdoba.

8 CUADRADO, Aníbal, “Trabajo a distancia, remoto o a domicilio en el marco de la crisis sanitaria”, Revista de Derecho Laboral-Actualidad, Suplemento Digital no 2: "El impacto del coronavirus en las relaciones laborales", Cita: RC D 1561/2020, Editorial Rubinzal Culzoni, Santa Fe, 2020.

9 CAPÓN FILAS, Rodolfo, Derecho del Trabajo, Editora Platense SRL., La Plata, 1998, p. 445. 
En un similar sentido se pronuncia Vázquez Vialard ${ }^{10}$ al observar que la buena fe ostenta una posición fundamental visto lo definitorio del carácter intuito personae del contrato de trabajo. Va de suyo entonces, que el modo de actuar de las partes durante la relación de trabajo debe de ajustarse - en la medida de su factibilidad - a la solidaridad y colaboración, obrando de forma leal y prudente, esperándose (como en una suerte de piso mínimo) que la dirección de los actos tienda en todo momento a evitar los daños inútiles e injustificados.

Otro sector de la doctrina ${ }^{11}$ entiende que la buena fe tiene dos acepciones distintas: la buena fe-creencia (partiendo ésta de la propia subjetividad del accionante, quien entiende que su conducta no causa ningún prejuicio) y la buena fe - lealtad (la que analiza el comportamiento objetivo, y no la convicción personal del acto). De ahí, la conclusión aunada es que en el Derecho del Trabajo se le debe dar mayor prevalencia a la última acepción, ya que el eje del análisis versará sobre el comportamiento desplegado por la parte (es decir, que su conducta sea leal, diligente, honrada, etcétera) dentro de un marco normal y esperable. Lo que puede traducirse también en la obligación de las partes de evitar causar daños inútiles, abruptos e intempestivos con sus actos.

En composé con lo indicado supra, y a la luz de un análisis de las medidas adoptadas durante la emergencia, es criterio de quien suscribe (sin ánimos de restar validez a las demás opiniones confrontadas y fundadas que puedan surgir) que los trabajadores que prestan servicios para alguna de las empresas no habilitadas para continuar con sus actividades presenciales (o que habilitadas, deban de cumplir con los protocolos de sanidad que imponen la rotación del personal) se encuentran ante la obligación subrepticia de continuar ejecutando sus tareas habituales u otras estrictamente análogas desde su lugar de confinamiento, siempre que esto se encuentre dentro de la medida razonable de sus posibilidades. ${ }^{12}$

El fin último de la normativa dictada durante la emergencia (es decir, sostener las fuentes de trabajo y conservar al empleo), no podrá ser recabado de forma única y exclusiva por las acciones que deba de tomar la parte empleadora (aunque sea ésta quien indefectiblemente se encuentra en la obligación de asumir las mayores responsabilidades debido a su posición jurídica). Por consiguiente, resulta dable de esperar que todos aquellos trabajadores se encuentren posibilitados de ejecutar tareas de forma remota desde su lugar de aislamiento (a través del teletrabajo u otra modalidad distinta a la presentista), continúe con su actividad laboral conforme el principio de buena fe. No siendo de recibo aquellas negativas fundadas en la simple negativa de no continuar prestando tareas por ser esta distinta a la modalidad bajo la cual ha sido contratado, encuadrando esta actitud dentro de los daños perjudiciales evitables que se esperan de las partes de la relación laboral.

Completamente distintos serán aquellos casos en los que deba de sustanciarse un cambio estructural en la naturaleza de las tareas del trabajador, o en los que éste no cuente con las herramientas necesarias y/o los conocimientos mínimos indispensables para

10 VAZQUEZ VIALARD, Antonio, Derecho del trabajo y de la seguridad social, Tomo 1, $7^{\circ}$ edición actualizada y ampliada, Editorial Astrea, Buenos Aires, 1996,p.131.

11 RODRIGUEZ MANCINI, Jorge, Derecho del Trabajo, 1a edición, Editorial Astrea, Buenos Aires, 2010, págs. 55 y 56.

12 Como se detallará más adelante, es un hecho real que no todos los trabajadores disponen de los medios necesarios para teletrabajar (a nivel tecnológico y ergonómico), ni de conexión fija a internet desde su lugar de aislamiento, ni de competencias digitales, o en otros supuestos, debido a la naturaleza de su actividad, es netamente imposible de que sea teletrabajable. 
ejecutar sus tareas de forma remota. En supuestos como los anteriores, no resultaría de recibo ninguna consecuencia disvaliosa que se pretenda endilgar al trabajador producto de sus impedimentos para adoptar la modalidad del teletrabajo durante la emergencia. No obstante, si de la propia voluntad del trabajador surge la aceptación de un significativo cambio en el tipo de tareas que realiza (por ejemplo, para evitar ser suspendido en los términos del artículo 223 bis de la LCT), esta novación del contrato deberá limitarse exclusivamente al tiempo de duración de la contingencia que impide al trabajador ejecutar su actividad de forma presencial.

Sin perjuicio de lo expuesto, comparto lo sostenido por Duarte ${ }^{13}$ en cuanto a que debe de existir una compensación de tipo económico a cargo del empleador por las tareas del teletrabajo realizado durante la pandemia. Si bien se reconoce como una de las ventajas del teletrabajo el ahorro de los costes de las empresas, ello no debe implicar un traslado de costes, por lo que no deberá ser el trabajador quien deba costear con su propio patrimonio todos los gastos necesarios para continuar ejecutando sus tareas de forma remota.

Nos encontramos transitando uno de los procesos transformacionales más rotundos de la historia del trabajo ${ }^{14}$ caracterizado por una improvisación masiva de teletrabajadores, quienes se han visto obligados a destinar un rincón de su lugar de aislamiento para ejecutar sus débitos laborales, poniendo a disposición de sus empleadores las conexiones de energía y de Internet, además sus herramientas de uso personal (como ser computadoras, teléfonos móviles, tablets, etcétera). Va de suyo entonces, que resulta esperable de un buen empleador la concesión de una compensación de tipo económico en favor sus subordinados (que hayan adoptado alguna de estas conductas). En definitiva, la buena fe ha sido la piedra angular de la normativa de emergencia, de ahí que las relaciones de trabajo que no se estructuren sobre ella, correrán un serio peligro de desmantelarse.

\section{El teletrabajo bajo la óptica de la informalidad y el género: ¿la pandemia nos afecta por igual?}

Desde que el COVID-19 ha sido declarado como pandemia por la Organización Mundial de la Salud, se ha repetido en los medios de comunicación que "nos encontramos ante un virus que afecta a todas las personas por igual, y que al momento de infectar no distingue entre raza, género, situación económica". Pese a que ser veraz la universalidad en relación a las posibilidades de contagio, esto no importa la existencia un grado equiparado de exposición universal, sino que por el contrario ciertos colectivos de personas se encuentran en una sensible situación de inferioridad para enfrentar la pandemia. Estas desemejanzas se manifiestan de forma clara en el mercado laboral, en especial en torno a la realidad por la que transitan los trabajadores informales y las mujeres, sea porque cuentan con reducidas posibilidades de ejecutar sus tareas de forma remota o por las estremecedoras condiciones bajo las cuales teletrabajan.

Según indican las proyecciones realizadas en una nota técnica de OIT Argentina ${ }^{15}$, se augura que como consecuencia de la pandemia en nuestro país podrían perderse entre 180.000 y 340.000 puestos de trabajo. Siendo que nuestro sistema laboral está diseñado

14 En igual sentido, CRUZ VILLALON, Jesús, Del coronavirus al contagio del teletrabajo. Efectos laborales de la declaración del estado de alarma (blog del autor). Entrada del día 20 de marzo de 2020.

15 OIT - Nota técnica. El COVID-19 y el mundo del trabajo en Argentina: impacto y respuestas de política, abril 2020. 
para proteger fundamentalmente a los trabajadores asalariados formales (y no al trabajo en todas sus formas, como brega la Constitución Nacional), quienes se encuentren laborando en los sectores informales no cuentan actualmente con la tutela efectiva provista por el régimen tuitivo, ni por la normativa de emergencia. La situación de vulnerabilidad por la que actualmente transitan los trabajadores informales se acrecienta aún más atento a la imposibilidad de acogerse a la modalidad excepcional del teletrabajo, sea porque la naturaleza de su actividad es de carácter netamente presentista o porque su empleador ha decidido no continuar otorgándole tareas, lo que incrementa abruptamente sus posibilidades de perder sus puestos de trabajo (si es que aún no los han perdido).

El teletrabajo, según los indicadores prepandémicos, ha sido una modalidad habitualmente reservada por las empresas a quienes ocuparan altos cargos gerenciales, por lo que las demás categorías inferiores debían ejecutar sus tareas de forma presencial. Conforme lo indicado por Boiarov ${ }^{16}$, en el año 2019 el teletrabajo (activo) en Argentina se distribuía principalmente en los sectores de administración, sistemas, y ventas, siendo una modalidad empleada tan solo por el $1.6 \%$ de los trabajadores en relación de dependencia. Dictado el aislamiento social preventivo y obligatorio producto de la pandemia, según OIT el teletrabajo ha sido la medida preferencial para continuar con la actividad laboral, siendo aplicada por el 55\% de las pymes que operan en el sector de servicios, y por el $46 \%$ de los profesionales independientes. A contraluz, el teletrabajo durante la pandemia solo ha podido ser utilizado por el $24 \%$ de las firmas en la industria y el $23 \%$ en el comercio ${ }^{17}$, sectores estos en los que predominantemente se encuentran los trabajadores informales de nuestro país ${ }^{18}$.

De los datos arrojados por los informes referidos anteriormente, surge la sensible situación de vulnerabilidad en la que se encuentran los trabajadores informales durante la pandemia COVID-19. Éstos además de prestar sus tareas habituales fuera de la tutela efectiva del manto protectorio del Derecho del Trabajo, se encuentran imposibilitados en su gran mayoría - de teletrabajar durante la pandemia, aumentando abruptamente las posibilidades de perder sus puestos de trabajo (si es que aún no lo han perdido). A fin de cuentas, concuerdo con Elías, en cuanto a que: "el virus mata a las personas vulnerables, la crisis económica provocada por la cuarentena mata a los empleos precarios. Y contra eso, por ahora, no hay tratamiento eficaz". ${ }^{19}$

Por otro lado, la obligada huida hacia el teletrabajo durante la pandemia, también encuentra en una especial situación de desprotección a las mujeres, cuya realidad es doblemente afectada, visto que el sector informal encuentra una mayor participación de las mujeres (por lo que hago extensivos los comentarios expuestos anteriormente), y que además quienes privilegiadamente se encuentran teletrabajando durante la pandemia, deben de realizar serios esfuerzos para intentar compatibilizar las tareas domésticas con las laborales. ${ }^{20}$

\footnotetext{
16 BOIAROV, Sonia, Telework and its effects in Argentina. Telework in the 21st Century An Evolutionary Perspective. The ILO Future of Work series. Edited by Jon C. Messenger, 2019. p.179, ISBN: 9781789903744.

17 OIT - Nota técnica, ob.cit.

18 Para mayor abundamiento, puede consultarse la nota del portal LA NACIÓN, titulada "Los sectores con más informalidad laboral", disponible en: https://www.lanacion.com.ar/economia/empleos/los-sectores-con-mas-informalidad-laboral- nid2129862.

19 ELIAS, Jorge, "La pandemia social, y sus consecuencias", Revista de Derecho Laboral- Actualidad, Suplemento Digital n 3: "El impacto del coronavirus en las relaciones laborales", Cita: RC D 1628/2020, Editorial Rubinzal Culzoni, Santa Fe, 2020.

20 En igual sentido, FRANCONI, Andrea Isabel, "El futuro del trabajo: inclusión e igualdad de género", publicado en Nuevas Tecnologías - Presente y Futuro del Derecho del Trabajo, ARESE, César(director), CHÉRCOLES, Ricardo León- FERRARIO, María de los Ángeles(coordinadores), Editorial Rubinzal Culzoni, agosto, 2019, ISBN: 978-987-30-1399-7.
} 
Pese a que los niveles de participación de las mujeres en el mercado de trabajo se encuentran en suba desde los últimos años, las brechas de género a la actualidad siguen siendo sumamente preocupantes.

Según lo expuesto por Lobato21, el porcentaje de desocupación femenina según los indicadores del tercer trimestre del 2019 asciende al 10,8\% (contra un 8.9\% de los hombres), siendo su precarización laboral de un $36 \%$ (contra un $34.2 \%$ de hombres). Por lo tanto, la situación prepandémica indicaba que la fuerza de trabajo de las mujeres era delicada, y a raíz de la pandemia COVID-19 se ha visto aún más comprometida, particularmente por sus serios inconvenientes para poder teletrabajar, por los problemas para conciliar la vida personal y familiar en razón de su trabajo de hogar no remunerado y por el exponencial aumento de la violencia doméstica durante el período de confinamiento obligatorio.

Según un reciente informe de CIPECC, el total potencial de trabajadores que podrían trasladar sus tareas habituales al mundo digital encuentra grandes diferencias según cual sea su carácter, jerarquía, tecnología y calificación. En materia de género la brecha que separa el potencial de teletrabajo entre hombres y mujeres asciende aproximadamente al 10\% (en favor de los hombres), lo que encuentra razón de ser - entre otras causales - en el conocido "techo de cristal" que impide la ocupación de las mujeres a los altos roles directivos de las empresas cuyos cargos son altamente teletrabajables. ${ }^{22}$ Aunque el gran porcentaje de las mujeres se desempeñen en el sector de servicios ${ }^{23}$ (el que se estima teletrabajable en una mayor medida que el resto de los sectores), la naturaleza propia de las tareas realizadas por las mujeres impide la posibilidad de que sean ejecutadas a distancia, ya que las mismas son imposibles de teletrabajar dada su necesidad de ser prestadas presencialmente (siendo un claro ejemplo la situación por la que transitan actualmente las trabajadoras de casas particulares).

Otra de las aristas que expone la vulnerabilidad de las mujeres durante la experiencia generalizada de teletrabajo obligatorio está determinado por su obligación de cubrir con dos trabajos en el hogar durante el confinamiento: los remunerados y los no remunerados. De ahí, que las horas laborales de las mujeres durante la pandemia del COVID-19 se han visto incrementadas en demasía debido al cierre temporal de las escuelas y de otros centros, que han obligado - indirectamente - a que las mujeres asuman dentro de los hogares, el rol de atender a las necesidades de sus hijos y/o de los adultos mayores. ${ }^{24}$

Su situación se torna ríspida además a tenor de lo dispuesto por la resolución 207/2020 del MTESS, que considera justificada la inasistencia de (solo) uno de los progenitores, o adulto responsable a cargo, que deba asumir el cuidado de un niño, niña o adolescente a raíz del cierre de las escuelas. Sin perjuicio del silencio y la confusión generada a raíz de la referida normativa según la obligación de remunerar o no estas ausencias ${ }^{25}$, según los

21 LOBATO, Julieta, "Impactos de género de la COVID-19 en las relaciones laborales". Revista de Derecho Laboral, Cita: RC D 2355/2020, Rubinzal Culzoni, Santa Fe-Buenos Aires, 2020.

22 ALBRIEU, Ramiro, Evaluando las oportunidades y los límites del teletrabajo en Argentina en tiempos del COVID-19, CIPECC, abril, 2020.

23 n palabras de FRANCONI: “...casi el 44.4\% de las mujeres se desempeñan en el sector "Servicios”, dentro del cual está incluido el servicio doméstico, actividad que ocupa el $98,7,6 \%$ de la esa mano de obra femenina en su gran mayoría sin formalizarse y Enseñanza, con el 73,6\%. Continuando con el sector "Servicios", le sigue en importancia la ocupación en la rama de "Comercio y Transporte", que demanda el 35,3\% de la fuerza de trabajo femenina.... FRANCONI, ob. cit.

24 OIT - Nota técnica, ob. cit.

25 Actualmente las posiciones doctrinales se bifurcan en dos: 1) que si deben ser remuneradas, entendiéndose que el espíritu de la legislación de emergencia es garantizar la intangibilidad de las remuneraciones de los trabajadores mientras dure la pandemia, además de que la lectura de la manda legal debe 
datos aportados por Lobato, en el $85,6 \%$ de los hogares de nuestro país son las mujeres las únicas responsables de los cuidados del hogar. ${ }^{26}$ Por lo que esta medida las reduce a escuetas opciones: atender de forma exclusiva (sin más alternativas) a sus tareas de cuidado no remuneradas y exponerse a la posibilidad de no disponer de su salario; o (¿en el mejor de los casos?), responder a dos trabajos de forma paralela y en simultaneo, pero únicamente recibiendo remuneración por uno de ellos.

Por último, resulta estremecedor el exponencial incremento de la violencia de género durante el confinamiento obligatorio, que implica un insoslayable impedimento para que las mujeres puedan continuar con normalidad la ejecución de sus débitos laborales a través de la modalidad del teletrabajo. Según los datos arrojados por el Gobierno de la Provincia de Córdoba, durante el aislamiento han aumentado más de cuatro veces las llamadas telefónicas para responder consultas y demandas, y concretar denuncias de violencia familiar y/o de género, y abuso sexual. Asimismo, en nuestra Provincia se ha incrementado vertiginosamente la violencia dentro de los hogares, receptándose por vía telefónica aproximadamente unas 2.800 denuncias, mientras que 2.346 denuncias fueron recibidas en la Unidad Judicial del Polo de la Mujer, de las que 1.946 fueron incoadas por violencia familiar. ${ }^{27}$

A raíz de todas las consideraciones vertidas resulta completamente falso y desajustado afirmar que la pandemia del COVID-19 ha afectado a todos los sectores por igual, ya que, en materia de posibilidades y condiciones de ejecutar el teletrabajo, los trabajadores informales y las trabajadoras mujeres se encuentran en una manifiesta situación de desventaja para poder continuar con su actividad de forma remota a través de esta modalidad. A fin de cuentas, podríamos arribar a la conclusión de que el teletrabajo durante la pandemia, pese a ser obligatorio a tenor de la literalidad de la normativa de emergencia, se ha configurado en la práctica como un verdadero privilegio gozado por unos pocos trabajadores, y como un calvario para muchas trabadoras.

\section{Apuntes para el futuro: ¿En qué contexto tecnológico enfrentamos el teletra- bajo de la pandemia?}

La digitalización siempre ha sido una asignatura pendiente para nuestro país y, en miras de fomentar su promoción, se erigió uno de los pilares de acción de la Coordinación de Teletrabajo, creada por el MTESS a través de la res. 147/2012. Dentro del catálogo de acciones que la Coordinación tenía a su cargo, tres de ellas ostentaban como principales objetivos los de reducir la brecha en materia tecnológica y fomentar la formación profesional en materia digital para permitir el acceso laboral y/o la readecuación profesional de los trabajadores. ${ }^{28}$ Pese a todos los esfuerzos por implementar esta modalidad de

\footnotetext{
realizarse conforme el principio in dubio pro operario; 2) que entiende que no deben ser remuneradas partiendo de un análisis literario, debido a que la referida resolución le confiere un trato diferenciado por denominarlas "faltas justificadas", a diferencia de las demás licencias otorgadas durante la emergencia en la que expresamente se dispone la obligación de remunerarlas..

26 LOBATO, ob. cit..

27 Datos extraídos de la página web oficial de prensa del Gobierno de la Provincia de Córdoba disponibles en: https://prensa.cba.gov.ar/informaciongeneral/violencia-de-genero-en-pandemia- una-situacion- critica/?fbclid=IwAR3JucfTlh2oS8m8SC1bbZNIEEpp7K3crtvJTQMnjJtShBSC7ZMA5FA8e40. 28 A modo ampliatorio destaco algunas de las acciones tendientes a lograr dichos fines: “... Asesorar permanentemente en materia de formación profesional respecto de las demandas de los sectores que requieran mejorar las competencias en TICs de los ocupados y desocupados, a fin de su incorporación a nuevas modalidades de empleo, entre ellas el teletrabajo; Llevar adelante la ejecución del Programa de Certificación de Competencia en Teletrabajo, en forma conjunta con la Dirección Nacional de Orientación y Formación Profesional, posibilitando la acreditación de los saberes y la experiencia adquirida informalmente por el reconocimiento de las calificaciones dentro de estándares de calidad; Coordinar acciones conjuntas con los MINISTERIOS DE CIENCIA Y TECNOLOGIA Y DE EDUCACION en proyectos que favorezcan la reducción de la brecha tecnológica a nivel nacional y en el diseño de herramientas de capacitación y formación en teletrabajo para docentes, profesores y alumnos de nivel Medio, Terciario y Universitario incorporando el teletrabajo como herramienta de inclusión social en todos los ámbitos alcanzados o alcanzables por esta modalidad...”.
} 
trabajo, el teletrabajo (previo al acaecimiento de la pandemia) ha sido de muy escasa difusión en la fuerza laboral nacional, limitándose a un alcance aproximado de solamente dos millones de trabajadores. ${ }^{29}$

Empero, como he referido en los puntos precedentes, la pandemia del COVID-19 se ha destacado por imponer la obligación indirecta de teletrabajar, que conllevó a raudamente improvisar millones de teletrabajadores, constriñendo a las empresas a reorganizar sus procesos productivos sin una planificación previa. Aunque el teletrabajo motivado por la emergencia sanitaria no ha sido estrictamente teletrabajo, la experiencia vivenciada encuentra su lado positivo en cuanto nos ha permitido dar un aventón en materia digital y ha colocado en el eje de las discusiones sociales a las modalidades vanguardistas de trabajo facilitadas por la tecnología. No obstante, el lado más oscuro de esta experiencia ha sido la notoriedad de las brechas en materia digital de nuestro país, que han impedido a grandes grupos de trabajadores continuar prestando sus tareas de forma remota, ya sea por falta de conexión a Internet, por falta de herramientas tecnológicas, o por falta competencias digitales para adaptarse a este cambio impuesto..$^{30}$

Una de las consecuencias (indirectas) de la pandemia, fue dejar de manifiesto la brecha digital que divide a nuestro país. Debemos de comprender, que estamos ante un fenómeno de tipología transversal, que nos afecta económica y socialmente, y que es al presente, lo que el analfabetismo era al pasado. ${ }^{31}$ Pese a ser conocidas nuestras carencias en materia de conectividad y la falta de competencias digitales de nuestra población, nos convertimos en especialistas en la postergación de su tratamiento. Y del mismo modo en que lo urgente no ha dejado tiempo para lo importante, la pandemia ha dejado a la luz la situación de sensible inferioridad en la que se encuentran millones de nuestros habitantes: sean trabajadores que no pudieron continuar ejecutando sus tareas de forma remota, o jóvenes que actualmente se encuentran esperando por el retorno de la educación presencial, ya que se encuentran involuntariamente imposibilitados de tomar sus clases online.

Aun cuando en el año 2011 la Asamblea General de la Organización de Naciones Unidas declaró que el acceso a Internet es un derecho humano fundamental por ser una herramienta necesaria para el progreso de la sociedad, la realidad en nuestro país es otra completamente distinta. En la América Latina y el Caribe, solamente un $67 \%$ de la población es usuaria de Internet, existiendo diferencias significativas tanto entre países como dentro de ellos, que obedecen principalmente a diferencias socioeconómicas y ubicaciones geográficas. ${ }^{32}$ En Argentina, según los datos arrojados del reporte realizado por la Cámara Argentina de Internet tan sólo el 56,1\% de los hogares tiene acceso a una conexión de Internet fija. ${ }^{33}$ Asimismo, según los indicadores del reporte digital global "We Are Social", quienes en nuestro país se encuentran posibilitados de ingresar a Internet, permanecen conectados aproximadamente un promedio de 4:44 horas diarias (a través de una conexión fija) y 3:30 horas diarias (mediante una conexión a Internet móvil), na-

\footnotetext{
29 BOIAROV, ob. cit.

30 En igual sentido, RODRIGUEZ FERNÁNDEZ, María Luz, "El trabajo durante la crisis sanitaria de la COVID19 desde la perspectiva de género", publicado en Noticias CIELO, mayo, 2020. Disponible en: www.cielolaboral.com.

31VALERA FERRIO, José, La brecha digital en España. UGT Comunicaciones, 2015, p. 9.

32 COMISIÓN ECONÓMICA PARA AMÉRICA LATINA Y EL CARIBE (CEPAL) / ORGANIZACIÓN

INTERNACIONAL DEL TRABAJO (OIT), "El trabajo en tiempos de pandemia: desafíos frente a la enfermedad por coronavirus (COVID-19)". Coyuntura Laboral en América Latina y el Caribe, N²2 (LC/TS.2020/46), Santiago, 2020.

33 CABASE, Estado de Internet en Argentina y la Región. Segundo semestre 2019.
} 
vegando durante la gran mayoría de este tiempo en redes sociales y en páginas web de ventas online. ${ }^{34}$

Estos indicios dan pauta de la abismal brecha digital que se encuentra zanjada en Argentina, la que genera una especie de doble barrera para el acceso al teletrabajo: la primera conformada por la falta de conexión y/o de insumos tecnológicos; mientras que la segunda está delimitada por la carencia de habilidades digitales que permiten ejecutar tareas a través del adecuado uso de las TICs. Resulta de supina importancia entonces, generar una conciencia sistémica y transversal de que el mundo que acostumbrábamos a concebir ha cambiado, debiéndonos de ajustar a las nuevas realidades para no encontrarnos excluidos de las oportunidades laborales que nos deparará el incierto futuro del trabajo, cuya única certeza (hasta el momento) es que se encontrará afectado por los avances de la tecnología ${ }^{35}$.

Va de suyo entonces, que la formación profesional en materia tecnológica debe tener un tratamiento preferente durante el futuro pospandémico, ya que será uno de los instrumentos idóneos que posibilitará el aumento de los porcentajes de ocupación y la colaborará en conservación de los puestos de trabajo que se encuentren atravesados por el cambio tecnológico. Para recabar dicho fin y virar hacia un futuro humano de calidad, requeriremos de un constante diálogo social, como de la promoción de políticas públicas y privadas que fomenten a la capacitación digital de nuestros trabajadores, y la alfabetización digital de los jóvenes estudiantes (a quienes actualmente se los forma para insertarse a un mercado laboral que ya no existe).

En otro orden de ideas, debe destacarse también que según surge un informe de CEPAL y OIT, en una encuesta realizada a 250 grandes empresas de nuestro país, el 93\% había decidido adoptar el teletrabajo como respuesta de la pandemia ${ }^{36}$. No obstante, esta realidad no se replica de igual manera en las pymes de nuestro país, que atraviesan otra realidad debido a su escasa inversión en materia digital. Según los datos arrojados en un informe de Accenture, solamente dos de cada diez empresas están invirtiendo (o han invertido en los últimos años) en tecnologías digitales como parte integral de su estrategia de negocio, demostrando estos indicadores una clara carencia de cultura digital por parte de nuestro sector empresario, el que se ha visto obligado a improvisar un teletrabajo durante la pandemia sin una estructura sistémica en materia digital, por lo que en muchos casos ha sido imposible de implementar la continuidad de la actividad empresarial de forma remota. ${ }^{37}$ Va de suyo entonces, que los planes estratégicos, programas y políticas que se diseñen en vías de facilitar la promoción del uso de las tecnologías, deberán a futuro ser un pilar para nuestro cambio de cultura, y apuntar no tan solo a los trabajadores y estudiantes, sino también a nuestras empresas nacionales.

Pese a lo indicado precedentemente, no puede dejarse de mencionar que además de la brecha digital, en nuestro país existe una abismal brecha social, delimitada por un 35\% de personas que actualmente viven debajo de la pobreza, situación que se ve sensiblemente incrementada en el rango etario de los menores de 14 años, donde uno de cada

\footnotetext{
34 ACCENTURE. El avance de la economía digital en Argentina. Optimizando las capacidades digitales para multiplicar el crecimiento. 35 En un similar sentido, SAAD, Carla, "Reconocimiento del "derecho a la capacitación continua" un reaseguro para el teletrabajo", s/d. 36 COMISIÓN ECONÓMICA PARA AMÉRICA LATINA Y EL CARIBE (CEPAL) / ORGANIZACIÓN INTERNACIONAL DEL TRABAJO (OIT), ob. cit. 37 ACCENTURE, ob. cit.
} 
dos de estos niños, es pobre según los datos del INDEC. ${ }^{38}$ La tan necesaria transformación digital de nuestro país sólo podrá ser factible luego de dar una solución concreta a nuestras distancias sociales. Son estas mismas brechas las que hoy enfrentan las realidades de trabajadores privilegiados que realizan el teletrabajo y de trabajadores despedidos, desocupados o imposibilitados de continuar con la ejecución de sus tareas; y que también distingue claramente a un grupo de estudiantes a los que les dictan clases vía Zoom y juegan a la Play Station en los recreos, de otros que se encuentran recluidos en sus hogares e imposibilitados de continuar recibiendo educación hasta que no retornen sus clases presenciales.

El teletrabajo durante el confinamiento y la implementación forzada de la tecnología, han sido experiencias útiles para la toma de conciencia sobre nuestras estrepitosas brechas sociales y digitales de nuestro país. A fin de cuentas, el futuro de la pospandemia dependerá en gran medida de las políticas que adoptemos conforme las experiencias vivenciadas.

"Nada cambia, si nada cambias"

Autor desconocido.

\section{v. Conclusión.}

Como reza la canción popular citada al comienzo del presente trabajo, el futuro llegó hace rato y de una forma en la que no lo esperábamos: con una modalidad de trabajo tecnológico temporalmente impuesta, con indicadores alarmantes en materia de género, con incrementos en los porcentajes de los sectores informales y con brechas estrepitosas a nivel social y tecnológico.

Todas las carencias y experiencias que han sido generadas (o expuestas) por la pandemia del COVID-19 deberán de ser el puntapié para direccionar el rumbo del sendero argentino durante la pospandemia, persiguiendo como fin un trabajo inclusivo y de calidad, que promueva la formación profesional digital para generar oportunidades laborales equitativas.

Quizás esto nos permita acercarnos a la tan añorada - y actualmente tan lejana - justicia social, por la que tanto brega el Derecho del Trabajo en su razón de ser.

38 Puede consultarse la nota del portal INFOBAE, titulada: "La pobreza aumentó al 35,5\% en 2019, afecta a 16,1 millones de argentinos y se prevé un mayor impacto por la inflación y la pandemia”. Disponible en: https://www.infobae.com/economia/2020/04/01/la-pobreza-aumento- al-355-por-ciento-en-2019afecta-a-161-millones-de-personas-en-todo-el-pais-y-se-preve-un- mayor-impacto-por-la-inflacion-y-la-pandemia/. 


\section{Referencias Bibliográficas}

- ACCENTURE. "El avance de la economía digital en Argentina. Optimizando las capacidades digitales para multiplicar el crecimiento".

- ALBRIEU, Ramiro, "Evaluando las oportunidades y los límites del teletrabajo en Argentina en tiempos del COVID-19", CIPECC, Abril, 2020.

- ARESE, César. "Cinco preguntas sobre el "jus variandi COVID-19" y la Res. METSS 279/2020", Revista de Derecho Laboral-Actualidad, Suplemento digital $n^{\circ}$ 3: El impacto del coronavirus en las relaciones laborales. Cita: RC D 1561/2020, Editorial Rubinzal Culzoni, Santa Fe, 2020.

- BOIAROV, Sonia, "Telework and its effects in Argentina. Telework in the 21st Century An Evolutionary Perspective", The ILO Future of Work series, Edited by Jon C. Messenger, 2019, ISBN: 9781789903744.

- CABASE, "Estado de Internet en Argentina y la Región. Segundo semestre 2019", disponible en: https://www.cabase.org.ar/wp- content/uploads/2019/12/CABASE-Internet-Index-II-Semestre-2019.pdf.

- CAPÓN FILAS, Rodolfo, Derecho del Trabajo, Editora Platense SRL, La Plata, 1998, I.S.B.N.: 950-536-105-X.

- COMISIÓN ECONÓMICA PARA AMÉRICA LATINA Y EL CARIBE (CEPAL) / ORGANIZACIÓN INTERNACIONAL DEL TRABAJO (OIT). “El trabajo en

tiempos de pandemia: desafíos frente a la enfermedad por coronavirus (COVID-19)". Coyuntura Laboral en América Latina y el Caribe, № 22 (LC/TS.2020/46). Santiago, 2020.

- CUADRADO, Aníbal. "Trabajo a distancia, remoto o a domicilio en el marco de la crisis sanitaria",Revista de Derecho Laboral-Actualidad, Suplemento digital n. 2: El impacto del coronavirus en las relaciones laborales. Cita: RC D 1561/2020, Editorial Rubinzal Culzoni, Santa Fe. 2020.

- CRUZ VILLALON, Jesús, "Efectos laborales de la declaración del estado de alarma”, publicado en Reflexiones y comentarios de cuestiones sociales y laborales de actualidad (blog del autor), 15 de marzo de 2020.

- DUARTE, David. "El trabajo en el lugar de aislamiento por COVID-19, ¿es teletrabajo?" en la revista socio-laboral Catorce Bis, edición N58, Primer semestre 2020,AATySS-Córdoba.

- ELIAS, Jorge, "La pandemia social, y sus consecuencias", Revista de Derecho Laboral-Actualidad, Suplemento digital $n^{\circ}$. 3: El impacto del coronavirus en las relaciones laborales. Cita: RC D 1628/2020, Editorial Rubinzal Culzoni, Santa Fe, 2020.

- FRANCONI, Andrea Isabel, "El futuro del trabajo: inclusión e igualdad de género". Publicado en Nuevas Tecnologías - Presente y Futuro del Derecho del Trabajo ARESE, César(director), CHÉRCOLES, Ricardo León- FERRARIO, María de los Ángeles(coordinadores), Editorial Rubinzal Culzoni, agosto, 2019, ISBN: 978-987-30-1399-7.

- GNECCO, Lorenzo, "Suspensión y despido en la emergencia", Revista de Derecho LaboralActualidad, Suplemento digital $n^{\circ}$. 4: El impacto del coronavirus en las relaciones laborales. Cita: RC D 1597/2020, Editorial Rubinzal Culzoni, Santa Fe, 2020.

- LOBATO, Julieta. "Impactos de género de la COVID-19 en las relaciones laborales", Revista de Derecho Laboral, Cita: RC D 2355/2020, Rubinzal Culzoni, Santa Fe-Buenos Aires, 2020.

- OIT - Nota técnica. "El COVID-19 y el mundo del trabajo en Argentina: impacto y respuestas de política",abril 2020.

- RODRIGUEZ FERNANDEZ, María Luz, "El trabajo durante la crisis sanitaria de la COVID19 desde la perspectiva de género", publicado en Noticias CIELO, mayo, 2020. Disponible en: www. cielolaboral.com.

- RODRIGUEZ MANCINI, Jorge, Derecho del Trabajo, $1^{\text {a }}$ edición, Editorial Astrea, Buenos Aires, 2010. ISBN: 978-950-508-910-9.

- SAAD, Carla. "Reconocimiento del "derecho a la capacitación continua" un reaseguro para el teletrabajo". Sin datos sobre su publicación. Se aclara que dicho artículo facilitado por la autora.

- VALERA FERRIO, José. “La Brecha Digital en España”. UGT Comunicaciones. 2015. Disponible en: http://portal.ugt.org/Brecha_Digital/BRECHADIGITAL_WEB.pdf

- VAZQUEZ VIALARD, Antonio, Derecho del trabajo y de la seguridad social, Tomo 1, $7^{\text {a }}$ edición actualizada y ampliada, Editorial Astrea, Buenos Aires, 1996, ISBN: 950-508-109-X. 